Accepted and forthcoming in Philosophy [0031-8191 (Print), 1469-817X (Online)] $<$ https://www.cambridge.org/core/journals/philosophy>. Please cite the published version.

\title{
Truth and Truthfulness in Painting
}

\section{Seeing truthfully}

In a memoir of his days as a gallerist in New York, Julien Levy reports the following exchange about one of Picasso's portraits of Dora Maar:

"Is this woman with one eye, or three eyes, a development of cubism?" I asked Picasso. "Not at all," he answered. "This double-profile, as it is called, is only because I keep my eyes always open. Every painter should keep his eyes always open. And how does that arrive at seeing truthfully, one eye or two eyes, you may ask? It is simply the face of my sweetheart, Dora Maar, when I kiss her." (Levy, 1977; 177)

We probably should not take Picasso at his word. The remarks artists make about their work are often teasing and evasive. And besides, while it is true that when you get close enough to kiss, the view from each of your eyes will be different, Dora is not portrayed from within kissing distance in any of these paintings. But the story is instructive. Ever since Plato, philosophers and psychologists have been fascinated by anamorphosis, trompe l'oeil, and other kinds of distortion and illusion in painting. Artists on the other hand more often say that they are interested in "seeing truthfully", even artists who play with forms as freely as Picasso does, and artists who are intensely painterly, thematizing the brushtroke and the substance and appearance of the paint. For instance, Gainsborough summarized his approach to painting with the remark, "I like the truth and daylight", while Van Gogh said that his aim in painting was to be simply honest before nature.

In this article, I shall explore the place of truth and truthfulness in figurative or representational painting and drawing. I do not mean to exclude the possibility that abstract art can be truthful, but I shall not consider it here. The concepts of truth and truthfulness are contentious, and I shall discuss both of them, and the relationship 
between them, both in general and in the specific case of painting. But my two starting-points are these.

First, a pair of definitions. Truth can be defined as agreement with reality. This is William James's phrase (1907, Lecture 6), but it is not a summary of the pragmatist theory of truth, or of any other theory. James claims that it is what any dictionary will tell you, which is not quite right. But he is right in saying that the definition should not be controversial. The quarrel begins when philosophers interpret it. As for truthfulness, when it is attributed to a person, it can be defined as a commitment to the truth-in other words, a resolute disposition to seek, accept, and communicate the truth. Truthfulness concerns communication above all, but the desire to communicate the truth cannot be separated from the desire to discover it or learn it, or from the willingness to accept it, once discovered or learned. A report or a description can also be described as truthful, in which case "truthful" commonly means the same as "true", although a truthful statement can also be one that expresses the truthfulness of its author, which is not exactly the same thing. I shall sometimes attribute truthfulness to persons and sometimes to communicative vehicles or their contents. The context will make it obvious which sense of the word is in play. Notice that truthfulness comes in degrees, so that one description may be more truthful than another. I shall assume that the same is true of truth.

My second starting-point is that truth is not the exclusive property of language, or communicated exclusively with words. Ernst Gombrich insisted that "a picture [...] can no more be true or false than a statement can be red or green", basing the claim on the authority of "logicians", adding that these are "not people to be easily gainsaid" (Gombrich, 1962; 56). But artists, historians and critics have always attributed truth and falsity to paintings, and a more cogent argument than Gombrich's appeal to authority would be required to proscribe the practice now.

Consider the paragone, the Renaissance debate about the comparative value of the arts. One of the principal questions was whether painting or poetry is better able to represent its subject truthfully. Here is Leonardo, making the case for painting.

La pittura serve a più degno sensu, che la poesia, e fa con più verità le figure delle opere di natura ch'il poeta. (Urbinas 1270; trat. 14) [Painting serves a 
nobler sense than poetry and represents the works of nature with more truth than the poet.]

Qual poeta con parole ti mettera in' anzi, o amante, la vera effigie della tua iddea con tanta verità, qual farà il pittore? (Urbinas 1270; trat. 18) [What poet can represent to you in words, oh lover, the true image of your ideal with as much truth as the painter will do?]

It is not plausible to dismiss this as an intellectual error, a metaphor, or a lazy or antiquated use of words. Perhaps painting does not represent the works of nature with more truth than a poet does. But if Leonardo's boast is wrong, the reason is not that only language is capable of communicating truth at all.

Turning to the historians and critics, Gombrich does not seem to have taken his own stricture about truth in painting too seriously. For example, he writes admiringly of Constable that he "wanted nothing but the truth" $(1951 ; 374) .{ }^{1}$ Nor was he the first to describe Constable's painting in this way. When Stendhal visited the French salon in 1824, he was thrilled by Constable's paintings. Classical landscapes, he insists, have "a style and an elegance, but lack truth", whereas, "the truth of [Constable's] charming works instantly strikes and delights us" (Harrison, 1998; 35). When Stendhal tries to explain what he means, he reaches for an old cliché, "the mirror of nature", which explains nothing at all. But this does not invalidate his original description, it only shows that it needs a better explanation.

Thus, my second starting-point is that logocentric conceptions of truth are mistaken. A plausible theory of truth will have to encompass truth communicated by paintings, sculptures, maps, and photographs as well as by language, and will have to accommodate the fact that Rembrandt's Lucretia portrays the victim of a rape more truthfully than Cranach's (Figs. $1 \& 2$ ) and that Sir Thomas Lawrence's portrait of the Duke of Wellington is less truthful than Goya's (Figs. $3 \& 4$ ). In both cases, we can assess the extent to which a painting agrees with reality no less than a description in

\footnotetext{
${ }^{1}$ Admittedly, the remark about Constable was written several years earlier than the one about "logicians"; but it was left untouched in all fifteen subsequent editions of The Story of Art, at least three of which include revisions.
} 
words. For if a painting represents something as being a certain way, and it is that way, then to that extent or in that respect, it is true; and if it represents something as being a certain way, and it is not that way, then to that extent or in that respect, it is false. This remains true whether we think of a painting as representing a particular person or place, such as the Duke of Wellington, a kind of object or scene, such as a soldier or a battle, or a subject or theme, such as war. For example, Goya's series of prints The Disasters of War represents its subject as truthfully as All Quiet on the Western Front or Life and Fate.

\section{Scepticism}

Anyone who investigates this topic will be struck by the scepticism or mistrust expressed by twentieth-century critics, historians of art, and philosophers about the very idea that a painter can "see truthfully", or communicate the truth. It is a kind of scepticism philosophers still direct against history, philosophy, and science, as well as painting, in other words, against every kind of work where truth is a value we aspire to and that measures our success.

Bernard Williams describes the attitude well in the first few lines of his book Truth and Truthfulness:

Two currents of ideas are very prominent in modern thought and culture. On the one hand, there is an intense commitment to truthfulness-or, at any rate, a pervasive suspiciousness, a readiness against being fooled, an eagerness to see through appearances to the real structures and motives that lie behind them. [...] Together with this demand for truthfulness, however [...] there is an equally pervasive suspicion about truth itself: whether there is such a thing; if there is, whether it can be more than relative or subjective or something of that kind. (Williams, 2002; 1)

Williams defends the orthodox doctrine that truth is a valid goal of enquiry, however difficult it may be to attain; and he argues that truthfulness-when it is attributed to a person-is composed of two "basic" virtues, accuracy and sincerity, the first of which is needed when we seek the truth, and the second when we communicate the truth to others $(2002,11)$. He does not define accuracy. Presumably it encompasses several 
characteristics: clarity of thought, precision, attention to detail, and so on. But he does define sincerity: "a disposition to make sure that one's assertion expresses what one actually believes" $(2002,96)$. (Notice the logocentric focus on assertion.)

Williams's approach seems to me partly right and partly wrong. His guiding thought that philosophers have focused on truth at the expense of truthfulness is astute. And he is right that truthfulness, when it is attributed to persons, includes both intellectual and moral dispositions. ${ }^{2}$ But he makes two connected mistakes. First, he draws a sharper distinction between the dispositions required for inquiry and communication than exists in reality; and second, as a result, the second basic virtue he postulates, sincerity is too narrowly tailored to the communicative act. The more inclusive concept of honesty is more apt. The reality is that both inquiry and communication call for clarity, precision, and attention to detail, and both call for honesty as well-the honesty to resist, as far as possible, the temptations that beset us to distort, or sanitize, or idealise, or simply falsify the truth, for the sake of some kind of satisfaction or advantage, or simply to avoid facing up to painful facts.

I shall return to the concepts of truth and truthfulness in due course; but I want to look now at the reasons art historians and philosophers have given to support their scepticism about the ability of art to record and communicate the truth.

Broadly, there are two kinds of reasons, both of which are comparable to the kinds of reasons that have been thought to support scepticism about truth in history, philosophy and science. But they generally take a special form when they are applied to painting, because in this case they rely on an assumption about what the truthfulness of a picture would have to consist in, if it existed, namely, in being a good copy or likeness, or a faithful imitation of what it depicts. They make this assumption, and then they protest either that a painting is never a faithful imitation or likeness of what it depicts, or that it is not actually an imitation or likeness at all.

The first reason for scepticism is the belief that painting is inevitably shaped by the local perspectives and conventions, the prejudices and values, that limit and control art, as they limit and control the whole of human life. All art is subjective-_la

\footnotetext{
2 Williams appears to deny that virtues are dispositions $(2002,125)$, but the text is not perfectly clear at this point, and in any case I prefer to use the term "disposition" in a sufficiently broad sense to include virtues.
} 
nature vue à travers un tempérament" (nature viewed through a temperament), as Zola put it-or worse, it is ideological and tendentious, and so it cannot be a true mirror or faithful representation of what it represents.

Thus, the great American art historian Meyer Schapiro insisted that there is no such thing as a "passive, 'photographic' representation" in art." "All renderings of objects", he insists, "proceed from values, methods and viewpoints which somehow shape the image and often determine its contents." (Schapiro, 1978; 195-196) Gombrich, who transformed the study of the visual arts in the 1960s, by re-thinking their relationship with psychology and optics, declared that "The innocent eye is a myth." (Gombrich, 1962; 250) And by the 2000s the suspiciousness Williams mentions, the "readiness against being fooled", had become the norm, so that even a study of ancient Greek vase-painting-not exactly the most radical branch of art history-could include a trenchant statement of a similar idea.

It is commonplace to celebrate the objectivity of artists, their powers of observation, and their tireless curiosity. In this way, representational systems take on all the authority of science: dispassionate observation, not historical milieu, determines stylistic development. (Neer, 2002; 28)

The second reason for scepticism is sometimes addressed to art in general, and sometimes to art in a so-called "realistic" style. Here the argument is that although we may imagine that a landscape by Courbet or Constable is a true likeness or imitation of reality, or a truer one than a landscape by Claude or Turner, works of art are actually composed of signs that are as arbitrary and conventional as words. Leo Steinberg-one of Tom Wolfe's three "kings of Cultureberg"-makes this sceptical point directly:

"Technical capacity in the imitation of nature" simply does not exist. What does exist is the skill of reproducing handy graphic symbols for natural appearances, of rendering familiar facts by set professional conventions. (Steinberg, 1972; 293) 
But if paintings are composed of conventional signs or graphic symbols, then styles of painting — such as the Geometric style in archaic Greece, or the style familiar from Japanese Ukiyoe prints-are like languages, inasmuch as they are simply alternative systems of semantic and syntactic rules. Hence paintings in one style cannot be truer or closer to reality than paintings in another style, any more than descriptions could be truer or closer to reality, purely because they are in Japanese or Greek. Some styles of art are called "realistic", but the label belongs to a false ideology. "The literal or realistic or naturalistic system of representation," Nelson Goodman concluded, "is simply the customary one." (Goodman, 1976; 38)

Taken together, these sceptical remarks represent a sea-change in attitudes towards art. For in the twentieth century, the very idea of how art and reality are related was transformed. But how much truth is there in this new orthodoxy? My view is that both lines of argument are partly right and partly wrong, and that only the part that is wrong supports the sceptical conclusions art historians and philosophers have drawn. I shall comment on them in turn under the headings Art and Objectivity and Art and Language.

\section{Art and objectivity}

It is not difficult to assess the first three quoted remarks. The first two-by Schapiro and Gombrich-are true, or broadly true, while the third is lamentably confused. But nothing that is true in any of them supports a sceptical view about the ability of art to record and communicate the truth.

Beginning with Schapiro, it is true that the visual arts "proceed from values, methods and viewpoints which somehow shape the image and often determine its contents." My only quarrel is with the preceding claim that there is no such thing as passive, "photographic" representation in art, which despite the scare quotes implies that photography is different. In fact, no medium of communication is inherently truthful or objective. For example, Philip Jones Griffith's Vietnam Inc. proceeds from values, methods and viewpoints just as much as Goya's The Disasters of War. But of course this does not undermine Schapiro's main point, on the contrary, it reinforces it.

It is also true, as Gombrich says, that "the innocent eye" is a myth. This is Gombrich's name for a popular idea about the artistic process that he did more than anyone else to debunk. It was based on the theory that our raw visual impressions of 
the world consist in patterns or arrays of colours, which we learn to interpretunconsciously and automatically-by means of concepts. As a result, our mature visual experience presents us with visible objects of specific kinds disposed in three dimensions, and we find it extremely difficult to see once again, as it is thought we did when we were infants, the raw patterns of colour visible objects present to the innocent eye.

According to the myth Gombrich opposes, the painter's task is to abstract from the framework of concepts, dissolve the boundaries between objects, recover the raw visual impressions the innocent eye perceives, and reproduce them on a surface. This theory of painting was widely accepted by psychologists, artists and critics in the nineteenth century, including John Ruskin, who expounds it in the passage from The Elements of Drawing where the phrase "the innocence of the eye" occurs:

The whole technical power of painting depends on our recovery of what may be called the innocence of the eye; that is to say, of a sort of childish perception of these flat stains of colour, merely as such, without consciousness of what they signify. (Gombrich, 1962; 250) ${ }^{3}$

Gombrich was right to reject this way of thinking about the artistic process, because the model of visual experience on which it depends is misconceived. Nineteenth-century psychologists inherited it from an older tradition in optics, enriched with Kantian philosophy, but it was a purely imaginary idea, not based on evidence, but rather, ironically, on a spurious analogy between the visual process and the task of seeing what a painting represents (Hyman, 2006; ch. 10).

However, neither the fact that the artistic process does not involve eliminating the influence of concepts on our visual experience of the world nor the fact that art proceeds from values, methods and viewpoints supports the sceptical conclusion that art cannot communicate the truth. This would follow only if values, methods, viewpoints or concepts made truthful communication impossible; but the opposite is

\footnotetext{
3 Monet was also an adherent of the myth (see Gage, 1993; 2009), and it persisted in the twentieth century, especially in relation to impressionist painting. For example, see Merleau-Ponty 1993; 59-75 and Schapiro 1997; 56.
} 
the case. Truthful communication would be impossible without values, methods, viewpoints, and concepts, because without them we could not learn to distinguish between truth and falsehood, or acquire the intellectual and moral dispositions- the clarity of thought, the attention to detail, and the honesty-on which truthfulness depends.

The third quotation is a different case. Here it is again.

It is commonplace to celebrate the objectivity of artists, their powers of observation, and their tireless curiosity. In this way, representational systems take on all the authority of science: dispassionate observation, not historical milieu, determines stylistic development.

This is a plainly sceptical remark. The claim here is that if we celebrate the objectivity of artists, their powers of observation, and their tireless curiosity, we assimilate art to science and ignore the influence of "historical milieu" on the development of artistic styles-such as in Greek vase-painting, in the sixth and fifth centuries BC, which is the author's subject.

So are the objectivity of artists, and their powers of observation, and their tireless curiosity another myth? Observation is at the heart of painting and sculpture at all times and in every culture, even if it is mainly the observation of other works of art. But it is true that the curiosity of artists and their powers of observation have been exaggerated, sometimes by artists themselves. One sign of this is that writers have generally described optical effects long before painters learned to represent them. For example, the appearance of sunlight on a wall or pavement is mentioned by Saint Bernard of Clairvaux; but there is no record of it in twelfth century painting. Jan Van Eyck's The Virgin in the Church, which dates from the late 1430s, may be the earliest example. Again, the French naturalist Georges Louis Leclerc described the varying colours of shadows in a lecture at the French Academy of Sciences in 1742, and similar observations were reported to the Royal Society in the 1790s. But they first appeared in English watercolours in the nineteenth century.

At the same time, artists have made discoveries, and not only about optical effects. For example, Greek vase-painters began to depict the posture of a running man with his forward arm opposite his forward leg between $530 \mathrm{BC}$ and $480 \mathrm{BC}$. It 
was not necessary to use a camera with a rapid shutter-speed to discover this, as it was when Eadweard Muybridge discovered how a horse gallops. But both discoveries enabled artists to represent particular kinds of motion with greater accuracy than before.

The record of visual discovery in art can be exaggerated or underestimated. But it is confused to imagine that if we celebrate the objectivity, observation, and curiosity of artists-the traits that make discovery possible-we are assimilating art to science, or ignoring the influence of "historical milieu" on the evolution of style. The root of the confusion is the idea that observation and milieu are competing factors, one of which operates in science and the other in art. This is doubly wrong. On the one hand, while many artists have acute powers of observation, the particular phenomena they observe and the techniques they use to observe them are influenced both by forces within the artistic tradition itself and by facts beyond it-by their "historical milieu". ${ }^{4}$ On the other hand, this is equally true of science. It applies to Newton and Darwin just as much as it does to Leonardo and Vermeer.

In sum, the opposition between "dispassionate observation" and "historical milieu" is false both in the case of art and in the case of science. So there are no plausible grounds here for scepticism about the ability of art to record and communicate the truth. Truth does not depend on transcending history-in either science or art.

\section{Art and language}

I said that there are two main reasons for scepticism concerning the ability of art to communicate the truth. The first is that art is never a faithful imitation of what it represents, because it is inescapably subjective or ideological, shaped by the artist's values, methods, viewpoint, and concepts, or those that were prevalent when it was made. The second is that art is not really an imitation at all: it consists in signs that are as arbitrary and conventional as words. Recall Steinberg:

\footnotetext{
${ }^{4}$ Baxandall 1972 is a classic study.
} 
"Technical capacity in the imitation of nature" simply does not exist. What does exist is the skill of reproducing handy graphic symbols for natural appearances, of rendering familiar facts by set professional conventions.

It is widely believed that some artistic styles are truer or closer to reality than others, but according to Steinberg artistic styles are just alternative systems of conventions, like languages or codes. The things we say are not truer or closer to reality if we say them in French, and we cannot expect them to be truer or closer to reality if we paint them in French either.

If this argument were sound, it would not follow that art is incapable of communicating truth, it would only follow that it does so in the way that language does, by means of signs that are as conventional as words. It is only if we add the premise that a truthful work of art would have to be a faithful imitation of its subject that we can draw the sceptical conclusion. But even without this premise, the argument still expresses the "pervasive suspicion" about truth Williams describes"whether there is such a thing; if there is, whether it can be more than relative or subjective or something of that kind"-because it implies that the verisimilitude we attribute to Caravaggio's or Velazquez's art is an illusion, created perhaps by the ascendancy their style attained, and the consequent ease and familiarity with which we "read" their work:

Realism is relative, determined by the system of representation standard for a given culture or person at a given time. Newer or older or alien systems are accounted artificial or unskilled. (Goodman, 1976; 37)

Again, I think there is something right about the analogy between artistic styles and languages. But it does not support this relativistic conclusion about realism, for the simple reason that languages-unlike codes-expand to express new ideas and new observations. ${ }^{5}$ "All you need is love" can probably be translated into every

\footnotetext{
${ }^{5}$ Art historians who seek to emphasize the importance of conventions in painting tend to refer indifferently to languages and codes (e.g. Gombrich, 1982; 278ff). But a code is a function that maps one alphabet onto another. Hence Morse and Semaphore,
} 
human language that is known, but the same is not true of " $\mathrm{E}=\mathrm{MC} 2$ " or "Energy is equivalent to mass". The difference between Italian painting in the trecento and the seicento, for example, is not like the difference between two languages or dialects, it is like the difference between the English of Chaucer and the English of Milton, the English of The Canterbury Tales and the English of Paradise Lost. The Canterbury Tales is not inferior to Paradise Lost, and Giotto was not a lesser artist than Caravaggio. But the language at Milton's disposal was far richer than the language available to Chaucer, and the same is true of the technical resources artists could draw on in the 1600s to depict drapery, anatomy, space, light and shade, by comparison with three centuries earlier. The terms "realism" and "naturalism" are often used to describe the result of this kind of expansion in expressive power. ${ }^{6}$

Hence, we can agree with the claim that artistic styles are comparable to languages without accepting the implausible idea that "the [...] realistic system of representation is simply the customary one" (Goodman), or that "'technical capacity in the imitation of nature' simply does not exist" (Steinberg). The analogy between art and language is a helpful corrective to traditional ways of thinking about the “imitation of nature”, such as Ruskin's (above, p. 000), or Leonardo's:

The painter, through himself alone, without the aid of anything appertaining to the various sciences, or by any other means, achieves directly the imitation of the things of nature. (Urbinas 1270)

But it is a mistake to assume that if this is rejected, then "the objectivity of artists, their powers of observation, and their tireless curiosity" must be rejected too; or to imagine if that if a painting cannot be a "passive, 'photographic' representation", it can only be a "handy graphic symbol".

The best way to prove that these are false choices is to look at actual examples. Take Leonardo's anatomical drawings (Fig. 5). They belie Leonardo's own description of his achievement; but they also confront writers who dismiss the objectivity and

for example, have precisely the same expressive power: any sentence that can be communicated in one can be communicated in the other. 6 The term "realism" also has other uses. See Hyman 2009. 
curiosity of artists on theoretical grounds with hard facts. A. Hyatt Mayor's comment about these drawings is particularly telling:

It does not matter that Leonardo lacked the academic system to do what Vesalius and Calcar were later to do as a team, for he had a rarer gift. He was the first man who, having found the plan in a limp confusion of tissues, and having unravelled the track of a wet thread of nerve, then could draw his exploration so unmistakeably that his drawings can forever guide any dissector in comprehending the structure in a tangle that opens under his knife. (Hyatt Mayor, 1984; 67)

Leonardo, Hyatt Mayor suggests, devised "a classic compromise between a copy of appearances and an abstract diagram of connections understood by the intellect", and he points out that this kind of "analytical picture-making" played an indispensable role in the development of modern science, which could not have been played by photography, because "the camera cannot think".

This is an especially illuminating description of truthful communication in the visual arts, because it shows how complex the task is. It explodes the myth of the innocent eye more effectively than philosophy can alone; but it also reveals a kind of shallowness in the sceptical reaction against the myth by some of the writers (not all) quoted above.

In sum, none of the arguments I have considered justifies scepticism about the ability of art to communicate truth. However, they do draw attention to a variety of untenable conceptions of truth and truthfulness in art, which span several centuries, and were promulgated by many of the greatest theorists of art, including Leonardo himself. I shall turn now to the task of explaining how we can correct these traditional conceptions of truth and truthfulness in painting, without embracing scepticism. In the next section, I shall focus narrowly on the problem of formulating an inclusive definition of truth. Then in the final section I shall consider what truth and truthfulness in painting consist in, and why they are of value.

\section{Truth in painting (La vérité en peinture)}


Philosophical ideas about truth in the twentieth century were invariably about truth communicated in words: true sentences, true statements made by uttering sentences, or true beliefs expressed by uttering sentences. ${ }^{7}$ Philosophers were divided on the question whether truth is a property of sentences themselves. Wittgenstein, Tarski and Quine held that it is, whereas Frege, Ramsey and Strawson held that it is not. But the assumption that language is the sole means by which truth is communicated was never a matter of dispute. But if we think about the history of art, and the history of discourse about art, this looks like a textbook case of tunnel vision-as if a theory of animal locomotion was confined to running and jumping and ignored swimming and flying, or a semantic theory was so fixated on nouns that it ignored verbs.

The exclusive focus on language as the vehicle of truth is one of two mutually reinforcing ideas which originated in the twentieth century and remain predominant today. The other is the deflationary idea that the statement that a certain proposition is true is equivalent to a statement of the proposition itself. For example, the statement that Tolstoy's famous dictum that all happy families are alike is true is equivalent to the statement that all happy families are alike. Frege expressed the idea as follows:

It is worthy of notice that the sentence 'I smell the scent of violets' has the same content as the sentence 'it is true that I smell the scent of violets'. So it seems, then, that nothing is added to the thought by my ascribing to it the property of truth. $(1977 ; 000)^{8}$

\footnotetext{
7 Wittgenstein's Tractatus is a notable exception (Wittgenstein, 1961; 2.21-2.222). But when Wittgenstein abandoned the picture theory of meaning, he seems to have abandoned the more inclusive conception of truth that he presented alongside it as well.
}

8 By a "thought" ("Gedanke"), Frege means what I call a proposition, i.e. the possible content of a belief or statement, such as that all happy families are alike. Propositions are also sometimes held to be sets of possible worlds-that is, the worlds at which the sentences that express them are true. But (despite some ingenious arguments to the contrary) the content of a belief or statement cannot be a proposition in this sense. For if it were, then one could not believe or state one necessary truth or falsehood without believing or stating every other necessary truth or falsehood, since every 
Frege's insight was elaborated in many different ways, but its association with logocentrism was a constant. For example, consider Quine's disquotational theory of truth. In Word and Object, Quine echoes Frege's remark, claiming that "to say that the statement 'Brutus killed Caesar' is true [...] is in effect simply to say that Brutus killed Caesar" (1960; 24); and in Philosophy of Logic, he develops the idea as follows:

The truth predicate is a reminder that, despite a technical ascent to talk of sentences, our eye is on the world. This cancellatory force of the truth predicate is explicit in Tarski's paradigm: 'Snow is white' is true if and only if snow is white. Quotation marks make all the difference between talking about words and talking about snow. The quotation is a name of a sentence that contains a name, namely 'snow', of snow. By calling the sentence true, we call snow white. The truth predicate is a device of disquotation. $(1970 ; 12)^{9}$

Quine's thought is this. A sentence placed in quotation marks, such as "Snow is white" is no longer a sentence, it is a singular term referring to the sentence. Hence, we can form a complete sentence by adding a predicate to it, for example, "'Snow is white' is an English sentence" or "Snow is white' is true". Quine's proposal that the truth predicate is a device of disquotation means that adding the predicate "is true" to

necessary truth and every necessary falsehood is true at exactly the same possible worlds, respectively, all and none.

${ }^{9}$ What Quine calls "Tarski's paradigm" belongs to the test Tarski proposed for the extensional adequacy of a definition of the predicate " $s$ is a true sentence of $\boldsymbol{L}$ ", where $\boldsymbol{L}$ is a formal language, such as the one Russell and Whitehead introduced in Principia Mathematica. Tarski argued that an extensionally adequate definition will entail an instance of the schema

" $s$ " is a true sentence of $\boldsymbol{L}$ if, and only if, $p$.

for every sentence of $\boldsymbol{L}$, where $p$ is a translation of $s$ into the language of the formula as a whole (in this case, English). See Tarski 1956. 
a singular term referring to a sentence has the same effect as removing the quotation marks, which would take us back to the original sentence. Hence the statement that the sentence "Snow is white" is true is equivalent to the statement that snow is white. ${ }^{10}$

Quine's theory of truth was meant to be iconoclastic. Truth, he tells us, has no more depth or substance than a pair of quotation marks. But it is iconoclastic in more senses than one, since it rules out ascribing truth to paintings. Consider what Quine calls Tarski's paradigm:

"Snow is white" is true if and only if snow is white.

This formula neatly illustrates the striking fact that a declarative sentence-every declarative sentence-says exactly what has to be the case in order for it to be true. ${ }^{11}$ For instance, the sentence "snow is white" says that snow is white, which is exactly what has to be the case in order for the sentence to be true. No property apart from truth has this remarkable characteristic. Some sentences say what has to be the case in order for them to be in French: "This sentence is in French", "This sentence is in the language spoken by De Gaulle", and so on. But every declarative sentence says what has to be the case in order for it to be true, and it does so without even referring to itself. This must tell us something fundamental about truth itself, and Quine's theory is designed to explain what it tells us.

Now the striking fact that every declarative sentence says what has to be the case in order for it to be true does not itself imply that truth is restricted to sentences. For equally, every picture shows exactly what has to be the case in order for it to be true. But Quine's disquotational theory cannot encompass paintings, because it

\footnotetext{
10 Notice that unlike Frege, Quine ascribes truth directly to sentences, as opposed to the thoughts or propositions that sentences express. For the sake of simplicity, I shall do the same in my discussion of Quine.

${ }^{11}$ If truth is properly applied to statements, thoughts or propositions, and not to sentences, we ought really to say that every declarative sentence says (or records) what has to be the case in order for the statement made or the thought or proposition expressed by uttering it to be true. See above, note 9.
} 
implies that the objects we describe as true (e.g. the English sentence "Snow is white") invariably belong to a language that also includes quotation-marks, logical connectives, and the word "true" itself_or can at least be exactly translated into such a language. But a painting cannot be translated into English, or any other language. Davidson makes this point nicely. He says, "A picture is not worth a thousand words, or any other number. Words are the wrong currency to exchange for a picture." (Davidson 2001; 263) We might say, for example, that Breughel's Icarus depicts a boy falling out the sky, the white legs disappearing into the green water, an expensive delicate ship, and so on. ${ }^{12}$ Or we might say simply that it depicts a landscape with the fall of Icarus. But every attempt to capture what a painting represents in words will be indeterminate and incomplete. So we cannot encompass pictures in a logocentric theory of truth with a translation manual.

Hence, Quine's theory of truth cannot be extended to include pictures. But the same holds for every other theory of truth developed on the basis of Tarski's formula or a variant of it. For example, it holds for Field's version of disquotationalism and Horwich's "minimal" theory of truth, although Field ascribes truth to utterances and Horwich to propositions. And it also applies to deflationary theories that owe less to Tarski, such as Grover's prosentential theory, Strawson's performative theory, and Künne's "modest" theory. All of these theories are about the way the truth predicate is used when we are talking about sentences, utterances, or the propositions they express, but a convincing theory of truth will apply equally to truth communicated by pictures and by words.

So, is it possible to express the deflationary idea in a way that avoids the persistent logocentric bias? Consider the following remark by Kotarbinski (Tarski's teacher), which begins by echoing William James's definition of truth:

In the classical interpretation, "truly" means the same as "in agreement with reality" [...] Let us ask what is understood by "agreement with reality". The point is not that a true thought should be a good copy or likeness of the thing of which we are thinking, as a painting or a photograph is. Brief reflection

\footnotetext{
12 These are all phrases from W.H. Auden's description of the painting in the poem “Musée des Beaux Arts” (Auden 1966).
} 
suffices to recognize the metaphorical nature of such comparison. A different interpretation of "agreement with reality" is required. We shall confine ourselves to the following:

Jan thinks truly if and only if

Jan thinks that things are thus and so, and things are indeed thus and so.

For instance, the central idea of the Copernican theory is [...] that the earth revolves around the sun; now Copernicus thought truly, for he thought that the earth revolves around the sun, and the earth does revolve around the sun. (Kotarbinski, 1966) ${ }^{13}$

Kotarbinski's position is this. Truth can be defined as agreement with reality. He does not reject this definition, he explains it. But he refuses to explain it in terms of copying or likeness-both of which are probably intended to evoke the then orthodox idea of correspondence to a fact. Instead, he explains it simply in terms of conjunction. Setting aside his preference for the adverbial construction (for thinking truly as opposed to true thought), a thought or theory or hypothesis is true, according to Kotarbinski, if and only if it is the thought or theory or hypothesis that things are thus and so, and things are thus and so.

Kotarbinski's position seems to me exactly right, except for two points. The first, of course, concerns painting and photography. For while the comparison between a thought and a painting or photograph may seem metaphorical after brief reflection, if the position I have defended is correct, less brief reflection shows that the comparison is not metaphorical at all. Truth is indeed agreement with reality. And this can be explained by means of conjunction-or alternatively by means of identity: a thought is true if, and only if, it represents things as being a certain way and they are that way. Alternatively, a thought is true if, and only if, the way it represents things as being is they way they are. But this applies to every kind of representation. The

13 The translation is by Künne $(2003 ; 333)$. 
Copernican theory is true if, and only if, the way it represents things as being is the way they are; and same applies to a painting or a photograph.

The second point is that this deflationary conception of truth is not as far removed from the idea that truth consists in likeness as Kotarbiński implies it is. (Indeed, there is nothing wrong with saying that truth is one kind of agreement and likeness is another.) For just as agreement in general-e.g. agreement in opinionand truth in particular can be defined in terms of identity or conjunction, so can likeness. For example, you and I agree about the way to make an omelette if, and only if, your opinion about the way to make an omelette is my opinion (identity), in other words, your opinion is such-and-such, and so is mine (conjunction). Equally, your bike and my bike are alike in colour, if, and only if, the colour of your bike is the colour of my bike (identity), in other words, your bike is such-and-such a colour, and so is mine (conjunction). The difference is that agreement in opinion consists in the identity of a content, whereas likeness consists in the identity of a property, or a range of properties.

\section{Truth and truthfulness in painting}

So far, I have argued for two main conclusions. First, the arguments we considered, which were thought to support scepticism about the capacity of painting for truthful communication, are fallacious. Truth and truthfulness are indispensable concepts in art criticism, and our use of them has not been successfully impugned. So we should not accept a theory of truth that is restricted in its scope to truth communicated in words. Second, truth in general can be defined as agreement with reality. This applies equally to truth communicated by pictures and by words. But it is not to be understood as copying or likeness in either case. It is explained in terms of identity or conjunction. Thus, we can accept the deflationary conception of truth while rejecting a formulation of it that is restricted to truth communicated by words.

Deflationary theories of truth can seem puzzling or disappointing. How can truth be a value - traditionally, one of the supreme values-if "nothing is added to the thought by my ascribing to it the property of truth"? Why should we care about truth? Why in particular should we care about truth in painting? And what is the point of going to all this trouble to prove that art can communicate the truth, if truth has scarcely more substance than a purely logical notion such as conjunction? 
There are three unsympathetic things to say in response. First, as we have just seen, likeness can also be explained in terms of conjunction. Second, the manner in which truth is defined does not cast doubt upon its value. Compare existence. We certainly care about the existence of individuals and species. For instance, many people care whether the orangutan will become extinct. If existence is merely a quantity-"at-least-oneness"—-this does not make their concern puzzling or absurd. Finally, if a truthful painting were properly defined as "a good copy or likeness of the thing", this would not explain its value. Virginia Woolf is reputed to have said, "Art is not a copy of the real world; one of the damn things is enough." Certainly, there is no intrinsic value in a copy. We can admire the skill involved in making it. But lies can require as much skill as the truth.

However, the puzzlement or disappointment is not entirely misplaced. For it does remind us how little a mere definition of truth can achieve-in particular, that it cannot explain why we should care about truth and truthfulness. In conclusion I should like to offer some tentative comments about this question, in three parts: the first concerns truth in general; the second concerns truth in painting; and the third concerns painting as an art. I can only indicate very briefly and with insufficient nuance how I believe we can approach each part of the answer. Let me reiterate that I am concerned here specifically with representational or figurative painting, as I have been throughout.

Concerning truth in general, describing truth as a value is a metonymy. ${ }^{14}$ The value of truth is the value of our awareness of truth, which is to say the value of knowledge. True propositions may be better than false ones for a certain kind of exercise in logic, but the proposition that snow is white is not superior to the proposition that snow is black as such. Considered simply as propositions they are on a par. However, awareness of truth certainly is valuable, both as a means and as an end. It is valuable as a means because it enables us to do the right things for the right reasons; and it is valuable as an end because it satisfies our curiosity, or at least has the capacity to do so (Hyman, 2015; ch. 8). This applies to painting just as much as to

\footnotetext{
14 "Value" in the Fregean term "truth value" (Wahrheitswert) has the mathematical sense of the output of a function, it does not mean value in the sense of worth.
} 
language, but of course there are differences, because when truth is communicated in painting it is shown rather than said.

Concerning truth in painting in particular, since painting is a visual medium, whatever we perceive or understand or learn from a painting is ultimately due to the forms and colours it is composed of and the forms and (often) colours it represents. ${ }^{15}$ The relationship between these sets of forms and colours-traditionally described in the language of imitation ${ }^{16}$ - means that paintings can communicate truth about appearances with an immediacy, intelligibility and power that language cannot match, as Leonardo understood. But it also means that paintings depend on symbols to communicate abstractions, such as the doctrine of the Trinity, and it can illustrate but cannot state a fact. For example, as I noted earlier, Breughel's Icarus depicts a boy falling out the sky, the white legs disappearing into the green water, and an expensive delicate ship. It may teach or remind us of the fact that that suffering takes place "while someone else is eating or opening a window or just walking dully along", as Auden claimed. But we cannot discover that it does so without interpretation, i.e. without an explanation (in words) of the painting's meaning-which can always be contested and revised.

Finally, concerning painting as an art, painting is not necessarily an artistic activity, any more than writing is. But representational or figurative painting does have a communicative function, even when this is deliberately stymied, for example, when painting decorates the interior of a sealed tomb. So it is admired for possessing the values that pictures, texts and other communicative vehicles can possess, or disparaged for failing to possess them, and truth is preeminent among these values. ${ }^{17}$

However, the arts in general, and painting in particular, also exemplify a process Quine famously discovered in moral training and in sport: the transmutation of means into ends. ${ }^{18}$ As Quine points out, "we come to relish the sport of fishing as

\footnotetext{
15 This may look like a restatement of the myth of the innocent eye, but in fact it has no implications regarding the nature or development of the visual system.

16 I examine this relationship in detail in Hyman 2013.

17 My use of the term communication is not intended to invoke any particular theory of communication or communicative intention.
}

18 Quine borrowed the phrase from Stephen 1843; 324. 
much as we relish the fresh trout to which it was a means." (Quine, 1979; 472) Quine writes with a light touch, but we should not underestimate the effect this process has on our appreciation of painting as an art. For it leads us to value the skills and dispositions that make up truthfulness as much as truth itself: clarity of thought, precision, attention to detail, and in a culture with the "pervasive suspiciousness" Williams describes, honesty above all.

What do these qualities look like in painting? ${ }^{19}$ There is no general answer, any more than there is a way they sound, when they are expressed in speech. But there are plenty of examples. Returning to Constable, we might say that his aim in painting was to communicate his love for the rural scenery of England-especially in his native Suffolk-by representing it as truthfully as he could. But what can the truthfulness of a landscape painting consist in, if it is not an accurate record of a specific place, like a surveyor's drawing or a map? Perhaps in avoiding different kinds of untruthfulness. Constable refused to idealise the landscape by tranforming it into an Arcadia inhabited by goddesses and shepherds, as Poussin and Claude Lorraine had done-though he revered Claude, and was inspired by his work. He shunned the picturesque. He described François Boucher's landscapes as "a bewildered dream of the picturesque", and "the pastoral of the Opera House", and he cordially loathed them. And he did not transform the landscape into an apparition or a dream, in the way that Turner-his contemporary and rival—did. "Golden visions", Constable wrote of Turner, "but only visions." When William Blake saw Constable's drawings, he said, "Why, this is not drawing but inspiration." To which Constable replied, "I meant it for drawing."

A portrait is a very different case, although here too the allure of untruthfulness needs to be resisted. Think again of Goya's portrait of the Duke of Wellington, especially the preparatory drawing, which was made in 1812, just after the defeat of the French at Salamanca, towards the end of the Peninsular War (Fig. 6).

\footnotetext{
${ }^{19}$ Lamarque and Olsen (2014) associate truthfulness specifically with "Romantic or expressive" conceptions of art, apparently because they equate truthfulness with sincerity. As I have explained (above, p. 000), I regard this as an excessively narrow understanding of truthfulness. Williams claims that the Romantic innovation was to associate sincerity with "personal authenticity" (2002; 172).
} 
However familiar we have become with photographs of exhausted soldiers in Stalingrad and Vietnam, it remains a haunting image, and it shows that even Goya's finished painting is a compromise between honesty and decorum. Truthfulness looks quite different in a landscape and a portrait; and it looks different in a portrait by Goya and one by Picasso. Proust's description of Chardin's pastel Self-Portrait with Spectacles as the "faithful, highly inquisitive translation of three original elements: character, life and the mood of the moment" $(1971 ; 377)$ does not apply to a Fayum mummy portrait. Perhaps the only valid generalization is that a truthful portrait is never a "passive, 'photographic' representation", and never depends on the "innocence of the eye". But it is evident that we can learn to recognize truthfulness in portraiture, and in other genres of painting, since we know where to look-and where not to look-for examples. For example, it would be surprising if a critic said that truthfulness was a quality she prized in Arcimboldo or Roy Lichtenstein.

There is no single source of value or overarching motive in art, any more than in human life generally. But the experience of encountering truthfulness face to face is one of the great gifts painting has to offer; and so a philosophical theory that rules this out should be rejected, whether it comes from logic or from the philosophy of art. ${ }^{20}$

John Hyman

Department of Philosophy, UCL j.hyman@ucl.ac.uk

\section{References}

Auden, W.H. (1966) “Musée des Beaux Arts”. In Collected Shorter Poems, 1927-1957, New York: Random House.

Davidson, D. (2001) “What Metaphors Mean”. In Inquiries into Truth and Interpretation, Oxford: OUP.

Frege, G. (1977) “Thoughts”. In Logical Investigations, Oxford: Blackwell.

20 I am most grateful to audiences in Uppsala and London and to a number of friends and colleagues for their comments on an earlier draft, especially Stacie Friend, HansJohann Glock, Andrew Huddleston, Paul Horwich, Jennnifer Judge, Peter Lamarque, and Elisabeth Schellekens. 
Gage, J. (1993) Colour and Culture, London: Thames \& Hudson.

Gombrich, E.H. (1951) The Story of Art, fourth edition, London: Phaidon. (1962) Art and Illusion, second edition, London: Phaidon.

Goodman, N. (1976) Languages of Art, second edition, Indianapolis: Hackett.

Harrison, C. et al. (1998), Art in Theory: 1815-1900, Oxford: Wiley-Blackwell.

Horwich, P. (1998) Truth, Oxford: OUP.

(2010) Truth-Meaning-Reality, Oxford: OUP.

Hyatt Mayor, A. (1984) Artists and Anatomists, New York: The Artist's Limited Edition.

Hyman, J. (2006) The Objective Eye, Chicago, Ill.: Chicago University Press. (2009), "Realism". In S. Davies, S. et al. (eds.), A Companion to Aesthetics, second edition, Oxford: Blackwell.

(2013) “Depiction”. In A. O’Hear (ed.), Philosophy and the Arts, Cambridge:

CUP.

(2015) Action, Knowledge, and Will, Oxford: OUP.

James, W. (1907) Pragmatism: A new name for some old ways of thinking, New York: Longman Green and Co.

Kotarbinski, T. (1966) Gnosiology. The Scientific Approach to the Theory of Knowledge, trans. O. Wojasiewicz, Oxford: Pergamon Press.

Künne, W. (2003) Conceptions of Truth, Oxford: OUP.

Lamarque, P.V. \& Olsen, S.H. (2014), “Truth”. In M. Kelly (ed.), Encyclopedia of

Aesthetics, second edition, Oxford: OUP.

Leonardo da Vinci, Urbinas 1270.

Levy, J. (1977) Memoir of an Art Gallery, New York: Putnam.

Merleau-Ponty, M. (1993) “Cézanne’s Doubt”, trans. M. Smith. In G. Johnson (ed.), The

Merleau-Ponty Aesthetics Reader: Philosophy and Painting, Evanston: Northwestern

University Press.

Neer, R.T. (2002) Athenian Vase-Painting, Cambridge: CUP.

Proust, M. (1971) Contre Sainte-Beuve etc. (Bibliothèque de la Pléiade), Paris:

Gallimard.

Quine, W.V.O. (1960), Word and Object, Cambridge, MA: MIT Press. (1970) Philosophy of Logic, Englewood Cliffs, NJ: Prentice Hall. (1979) "On the Nature of Moral Values", Critical Inquiry 5. 
Schapiro, M. (1978) 'The Nature of Abstract Art'. In Modern Art: 19th and 20th

Centuries, New York: George Braziller.

(1997) Impressionism: Reflections and Perceptions, New York: George Braziller.

Steinberg, L. (1972) “The eye is part of the mind”. In Other Criteria, Oxford: OUP.

Stephen, J. (1843) "Ignatius Loyola and his Associates”. In Critical and Miscellaneous

Essays, Philadephia: Carey \& Hart.

Tarski, A. (1956) “The Concept of Truth in Formalized Languages”. In J.H. Woodger

(ed.), Logic, Semantics, Metamathematics, Oxford: OUP.

Williams, B.A.O. (2002) Truth and Truthfulness, Princeton, NJ: Princeton University

Press.

Wittgenstein, L. (1958) Philosophical Investigations, trans. G.E.M. Anscombe, second edition, Oxford: Basil Blackwell.

(1961) Tractatus Logico-Philosophicus, trans. D.F. Pears \& B.F. McGuinness,

London: Routledge \& Kegan Paul.

\section{List of Illustrations}

1. Rembrandt van Rijn, Lucretia, 1666. Oil on canvas. Minneapolis Institute of Art, Minneapolis, Minn.

2. Lucas Cranach d. Ä., Lucretia, ca. 1530. Oil on canvas. Neue Residenz, Bamberg.

3. Sir Thomas Lawrence, The Duke of Wellington, 1815-16. Oil on canvas. Apsley

House, London.

4. Francisco de Goya, The Duke of Wellington, 1812. Oil on canvas. National Gallery, London.

5. Leonardo da Vinci, Myology of the shoulder region, ca. 1510. Pen and brown ink. 289 x 199 mm. Royal Library, Windsor.

6. Francisco de Goya, Arthur Wellesley, 1st Duke of Wellington, 1812. Red chalk over graphite. 235 x 177 mm. British Museum, London. 


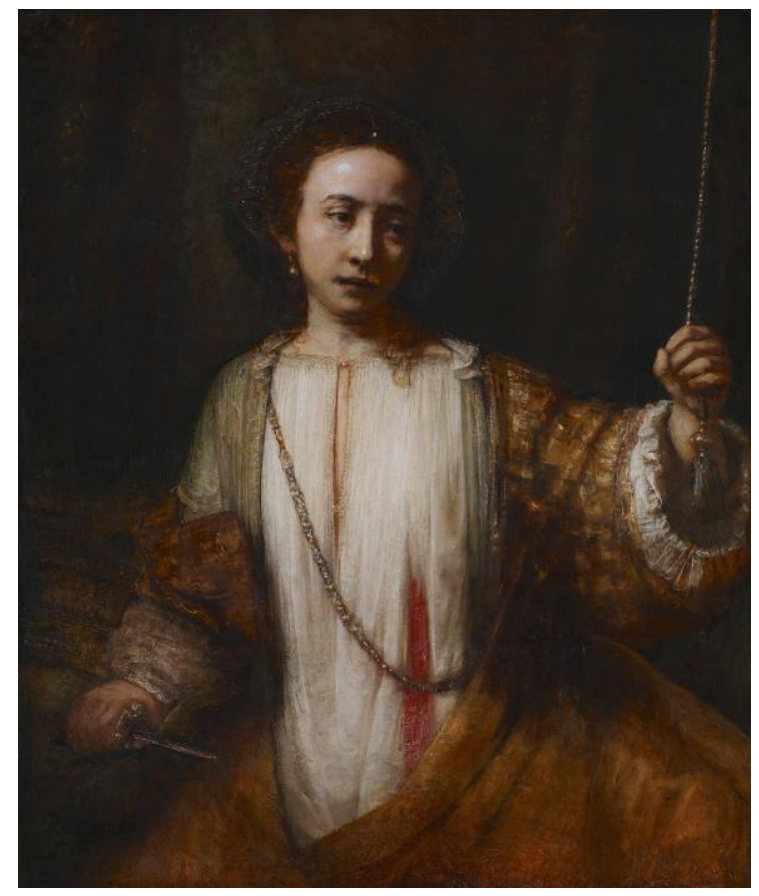

1. Rembrandt van Rijn, Lucretia, 1666. Oil on canvas.

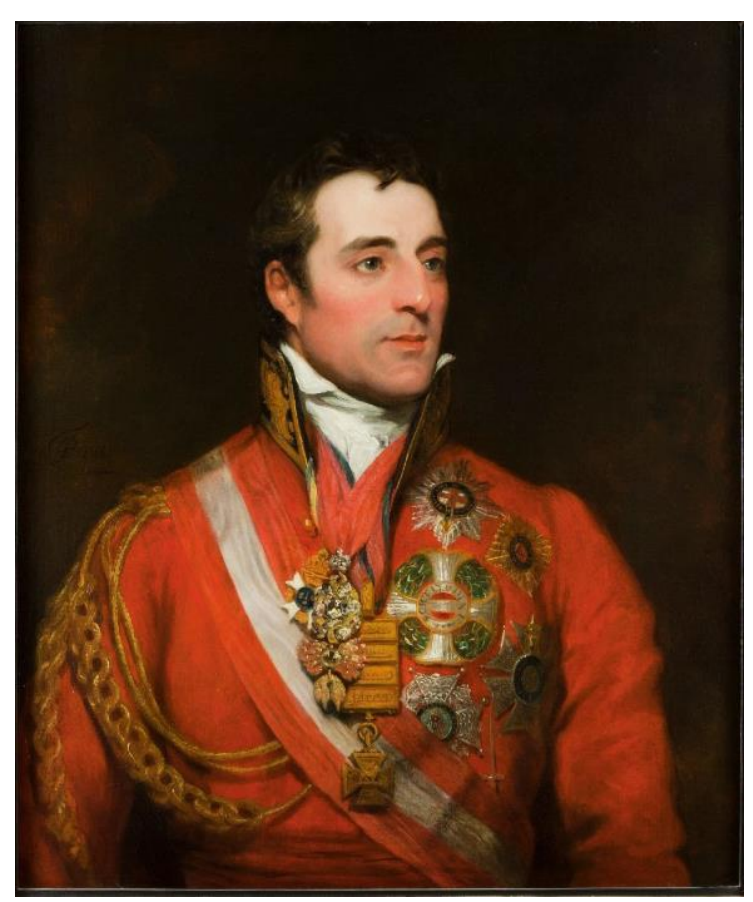

3. Sir Thomas Lawrence, The Duke of Wellington, 1815-16. Oil on canvas.

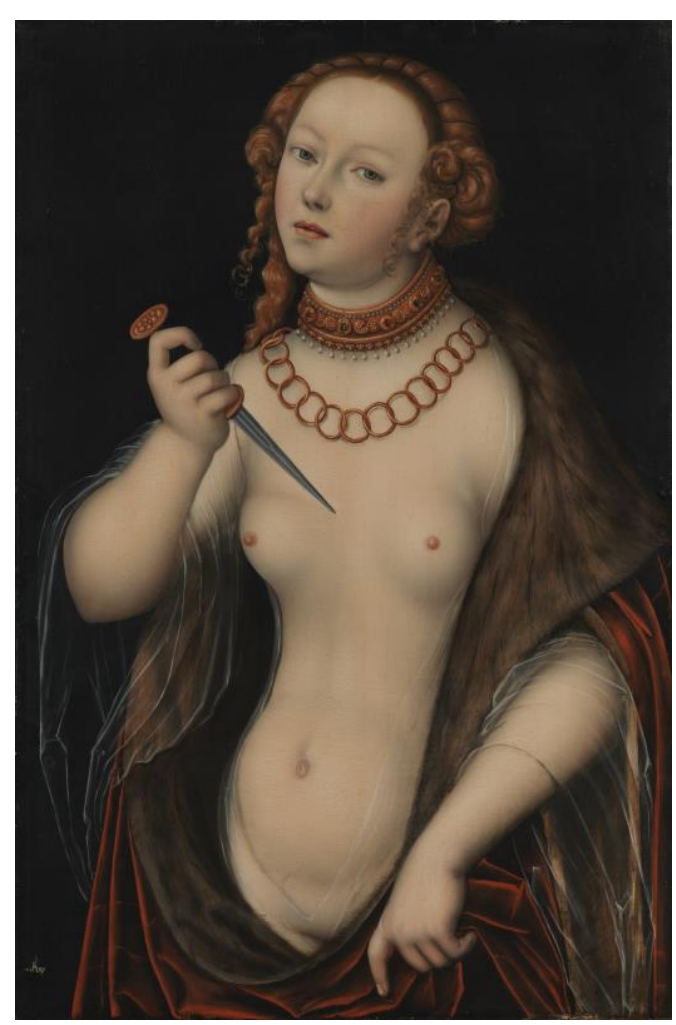

2. Lucas Cranach d. Ä., Lucretia, ca. 1530. Oil on canvas.

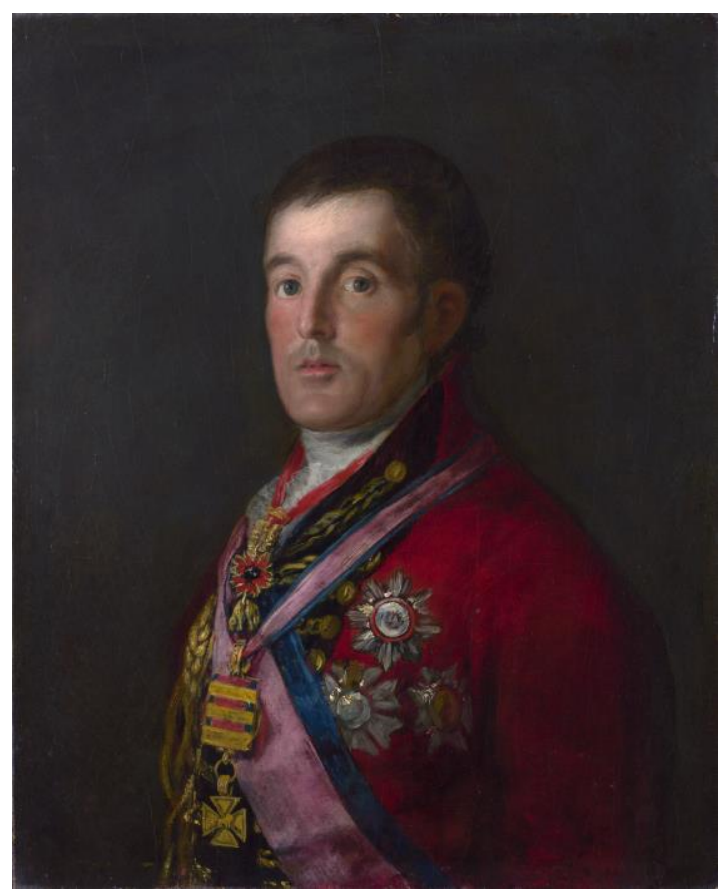

4. Francisco de Goya, The Duke of Wellington, 1812. Oil on Canvas. 


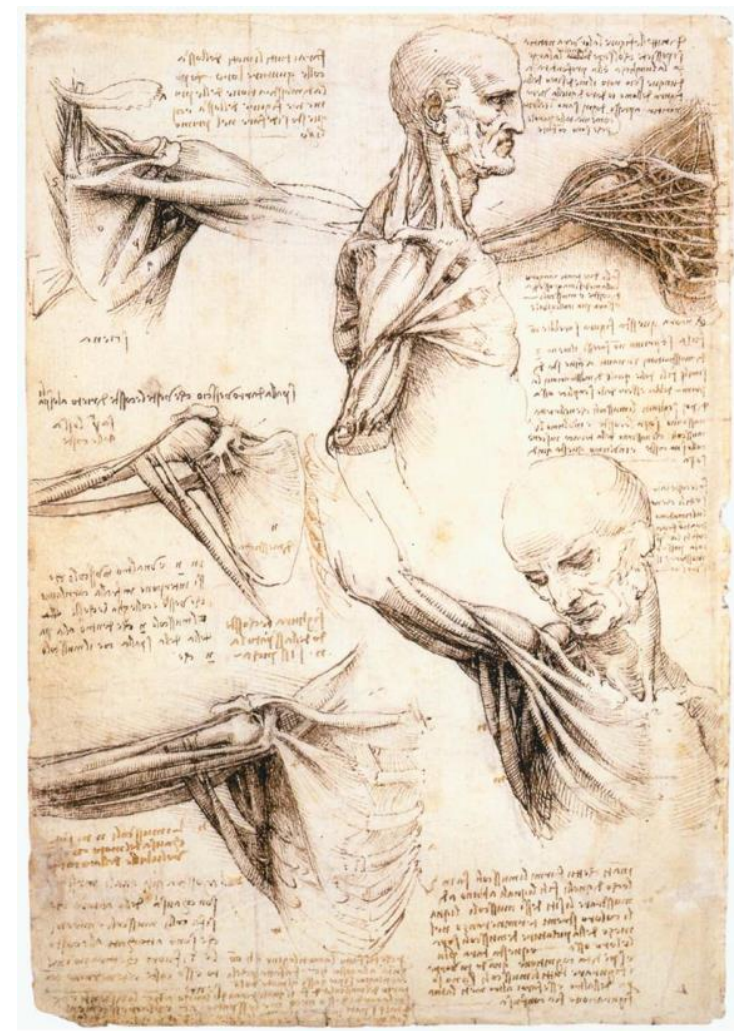

5. Leonardo da Vinci, Myology of the shoulder region, ca. 1510 . Pen and brown ink.

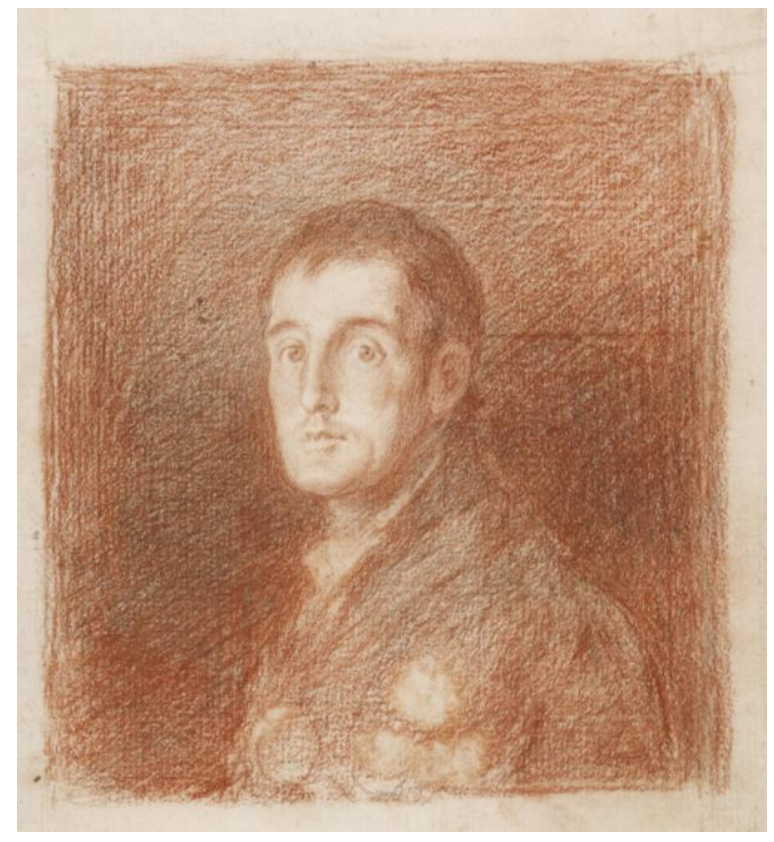

6. Francisco de Goya, Arthur Wellesley, $1^{\text {st }}$ Duke of Wellington, 1812. Red chalk over graphite. 